\title{
THE CONTRIBUTION OF GEOMATIC TECHNOLOGIES TO BIM
}

\author{
K.Pavelka ${ }^{1}$ iD, E.Matoušková ${ }^{1}$, K.Pavelka,jr. $^{1}$ \\ ${ }^{1}$ Czech Technical University in Prague, Faculty of Civil Engineering, Dept. of Geomatics, Thakurova 7, Prague 6, 16629, Czech \\ Republic, pavelka@fsv.cvut.cz
}

Commission TC V / WG 7 and TC IV / WG 6

KEY WORDS: BIM, photogrammetry, laser scanning, cultural heritage, 3D documentation

\begin{abstract}
:
There are many definitions of the commonly used abbreviation BIM, but one can say that each user or data supplier has different idea about it. There can be an economic view, or other aspects like surveying, material, engineering, maintenance, etc. The common definition says that Building Information Modelling or Building Information Management (BIM) is a digital model representing a physical and functional object with its characteristics. The model serves as a database of object information for its design, construction and operation over its life cycle, i.e. from the initial concept to the removal of the building. BIM is a collection of interconnected digital information in both protected and open formats, recording graphical and non-graphical data on model elements. There are two facets: a) BIM created simultaneously with the project, or project designed directly in BIM (it is typical of new objects designed in CAD systems - for example in the Revit software) or b) BIM for old or historical objects. The former is a modern technology, which is nowadays used worldwide. From the engineer's perspective, the issue is the creation of BIM for older objects. In this case, it is crucial to obtain a precise 3D data set - complex 3D documentation of an object is needed and it is created using various surveying techniques. The most popular technique is laser scanning or digital automatic photogrammetry, from which a point cloud is derived. But this is not the main result. While classical geodesy gives selective localized information, the abovementioned technologies give unselected information and provide huge datasets. Fully automatic technologies that would select important information from the point cloud are still under development. This seems to be a task for the coming years. Large amounts of data can be acquired automatically and quickly, but getting the expected information is another matter. These problems will be analysed in this paper. Data conversion to BIM, especially for older objects, will be shown on several case studies. The first is an older technical building complex transferred to BIM, the second one is a historical building, and the third one will be a historic medieval bridge (Charles Bridge in Prague). The last part of this paper will refer to aspects and benefits of using Virtual Reality in BIM.
\end{abstract}

\section{INTRODUCTION}

\subsection{What is a BIM?}

BIM is a very popular acronym used in the last decade. The abbreviation BIM has been used more generally only since 2002 (Dekker, 2017). The principles of information modeling have been known since 1974 and in the last few years they have shifted from the theoretical level into practice. There are a number of definitions for BIM that differ in the use of the system itself. Building Information Modeling or Building Information Management (BIM) is a digital model representing a physical and functional object (building) with its characteristics. The model serves as a database of information about the building for its design, construction and operation throughout its life cycle, ie from the initial concept to the removal of the building. BIM is a collection of interconnected digital information in protected and open formats, a recording of graphic $(2 \mathrm{D}, 3 \mathrm{D})$ and non-graphic data about elements (elements) of the model. The 3D model itself is often mistaken as an information model of a building, even in professional circles. It is important to say here that BIM inherently includes not only its own information, but also rules for handling it; the 3D model is only one of many possible ways of presenting this information. The data must be compatible with used software systems and must be accessible to users, project participants, and must serve for the purposes of modeling, preparation and implementation, operation, maintenance and restoration of the building. The joined information creates a virtual model of the building, both spatial, time, cost, etc., from individual elements. These can be not only buildings, but also linear structures, bridges, etc. The basis of BIM is a 3D model of the object (building). And it can be a problem solved by using methods of geomatics or geodesy.

\subsection{Using BIM for new constructed objects}

Nowadays, buildings or constructions are already designed in BIM. However, it is used for larger buildings (constructions), using BIM for small houses or cottages is still in its infancy because of the input price and the maintenance of the system. Modern BIM brings long-term benefits in the definition and position of utility networks (power lines, water supply, sewerage, low - voltage networks), construction elements and monitoring their lifetime, resulting in cost savings, and keeps the building in good condition. System maintenance is a necessary part of BIM. Here, it is necessary to take into account the development of computer technology and software, which is very fast.

\subsection{Using BIM for old or historical objects}

In relation to older or even historical buildings or sites, there is a totally different approach (Pavelka,jr., Michalík,2019). For older buildings or structures, we usually have classic 2D plans and cross-sections from the original construction documentation (Hůlková et al, 2016). This is a good basis for creating a new information system, but much other information (3D, materials, 
networks, etc.) needs to be added (Matoušková, Hůlková, Šedina, 2016). For historical buildings, there is either no solid documentation at all, or it was created purposefully during reconstructions and it is certainly not uniform or complete (Tuttas et al, 2014). Usually, it is better to create a completely new and accurate documentation, corresponding to today's requirements. Why should BIM be created for historic buildings? The answer is logical - when it comes to truly historic buildings, we try to keep them in good condition for a long time and we usually want to use them for living (Poloprutský, Fraštia, Marčiš, 2019). Many parts of historical buildings are unique or made by old technologies. This must be accepted from today's view on heritage care (Pavelka, 2017).

\section{CONTRIBUTION OF GEOMATICS}

\subsection{BIM or 3D GIS?}

From the perspective of geomatics or geodesy, BIM can be compared to 3D GIS. This parallel is suitable because similar tools are used in many cases for system creation and administration. In both cases, the basis is an accurate and credible 3D model, supplemented by thematic information.

\subsection{Technology}

In terms of technology, conventional geodesy can be traditionally used; but this is relatively slow. The aim is fast and if possible automatic 3D documentation of the entire building inside and outside. Today, we have several options with full or partial process automation:

1) Advanced modern geodesy with semi-automatic devices (total stations often with a camera and scanning possibilities),

2) laser scanning (terrestrial stop and go technology), (Fig.1), (Gleason, 2013),

3) mobile laser scanning (exteriors of buildings or linear constructions and bridges) using a special instrument mounted on a car equipped with INS (inertial navigation system), (Fig.2),

4) indoor mobile laser scanning (indoor parts of buildings) using hand-held equipment or a special trolley using an inertial unit, (Fig.3), (Kaijaluoto et al, 2015),

5) digital intersection photogrammetry (IBMR image based modeling and rendering), aerial photos, drones etc. (Šedina, Housarová, Raeva, 2018).
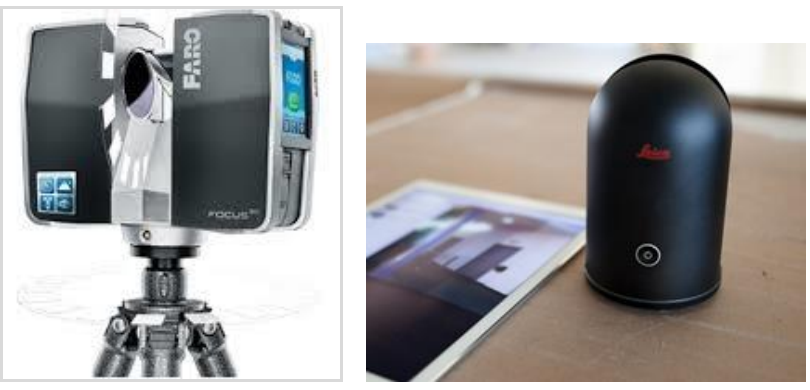

Figure 1. Examples of laser scanners (terrestrial laser scanner FARO, Leica BLK360).
The use of the above technologies depends on the object, the price of the order, the accuracy and the capabilities of the persons who carries out the documentation.

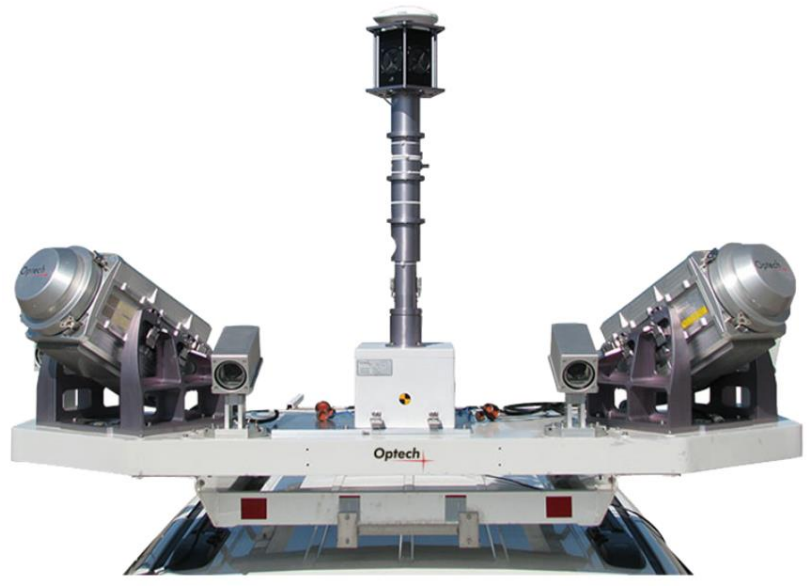

Figure2. Mobile laser scanner (Lynx)
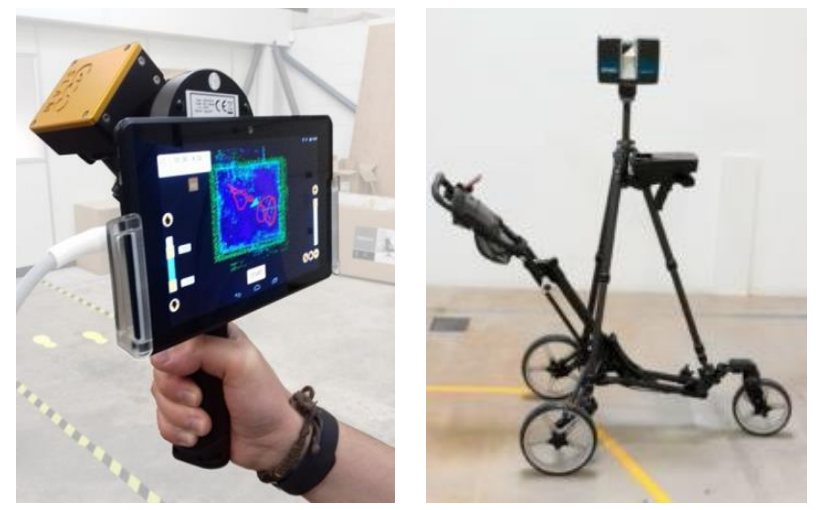

Figure 3. Indoor laser scanners (GEO Slam) Zeb REVO (left), Faro (right)

\subsection{Virtual reality}

Virtual reality, like BIM, is again a very often used acronym. In modern manipulations with spatial data, the emphasis is often on visualization. Nowadays, Virtual Reality is used with success for data visualization. In this case, it is appropriate to say that this technology has come a long way in the last years. There is:

1) Augmented Reality (It is a term used for a real image of the world accompanied by computer-generated objects.). Using this it is possible to replenish real objects with non-existent elements.

2) Virtual Reality (It is about creating a visual experience that gives an impression of reality using devices connected to a computing unit that generates realistic perceptions for the user. It is commonly a stereoscopic imaging device in the form of special glasses with sensors for sensing their position. It is based on a 3D model of an object or surrounding reality with a texture in the computer memory), (Fig.4).

A significant benefit of VR is that someone creates a VR model and that others can browse or view it without being there. This is extremely important, for example, in the analysis of building structures and in archaeology or heritage care, especially in 
remote, dangerous or hard-to-reach places (Shirer, Torchia, 2017).

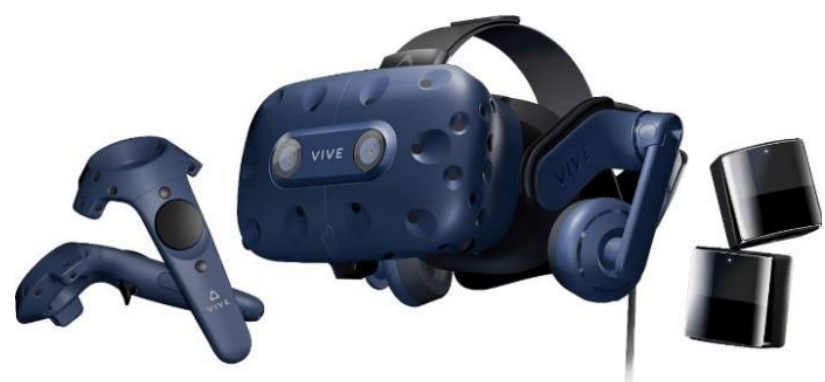

Figure 4. Typical VR workplace with HTC2 glasses and lighthouses.

\section{CASE PROJECTS}

Here, we would like to show some examples how BIM or a general, common 3D information system of an object can be created and how it was developed.

\subsection{Charles Bridge in Prague (beginning of BIM)}

In 2004-5, the documentation of an important Czech and worldwide monument - historic Charles Bridge in Prague - was made. The methods of laser scanning and IBMR digital photogrammetry were not common at that time. Nevertheless, the bridge model was geodetically measured, the vector skeleton was defined by laser scanning, and the details and texture were created by single image digital photogrammetry. The resulting vector model in ACAD contained all the joints between the stone blocks and, finally, the model was covered with the texture from photos. Additionally, on one bridge arch and two pillars, historical and geological analysis of all stones was made. Each stone was identified by its type, origin, wear, defects, stonecutter marks, degradation, etc. (altogether 20 parameters), (Fig.5). Mouse clicking on a stone in the model will depict the related data (Fig.6). It was also possible to display its photograph with the near surroundings. It was already clear that for other experts this information would have to be concentrated in a $3 \mathrm{D}$ viewer. However, at the beginning of a new century, no suitable software for this project existed. A unique system was programmed in the laboratory of photogrammetry at the Czech Technical University in Prague that would now be referred to as BIM (Pavelka et al, 2016).

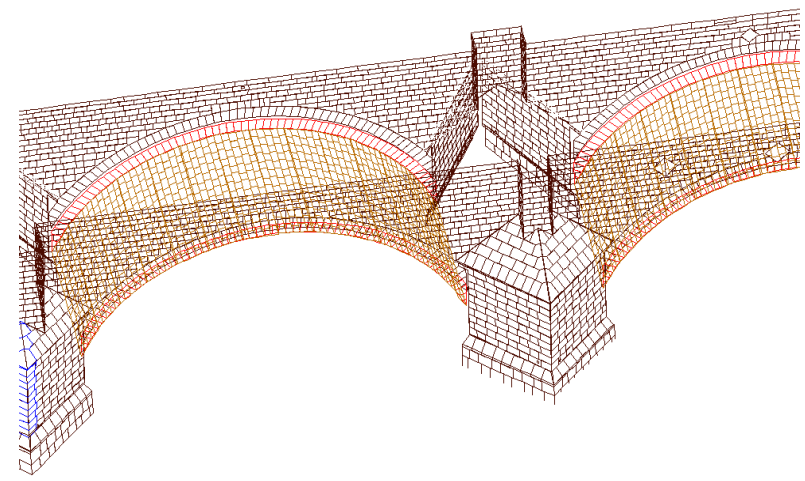

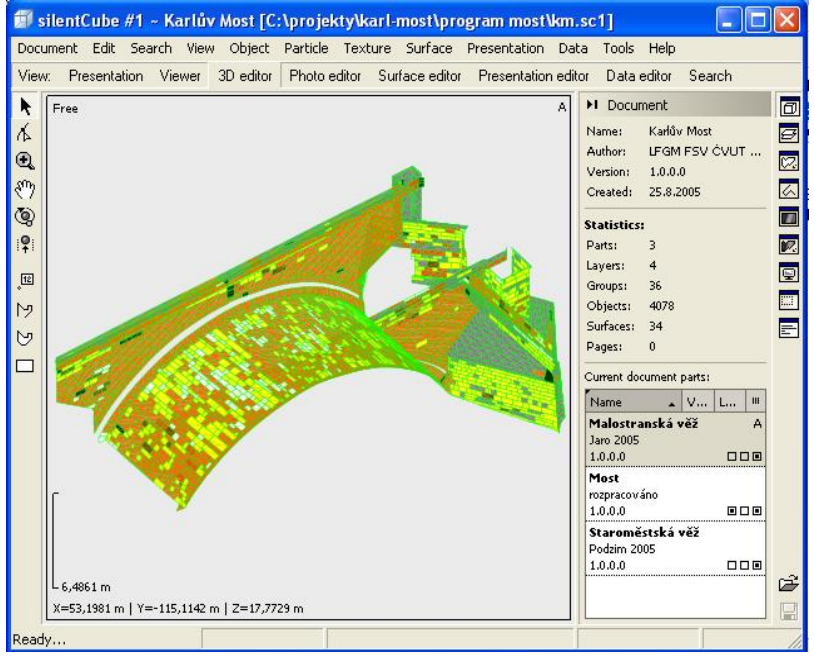

a)

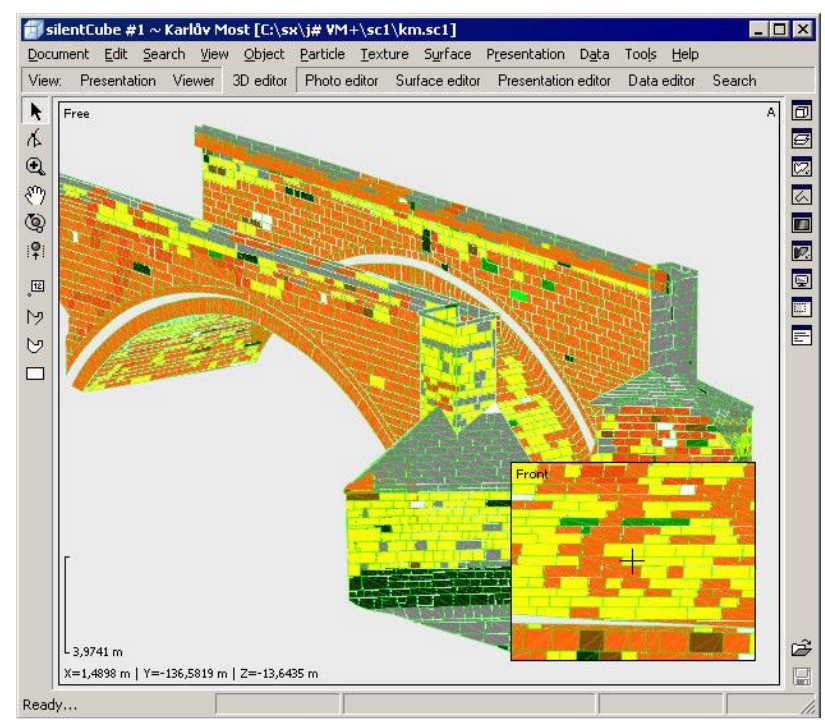

b)

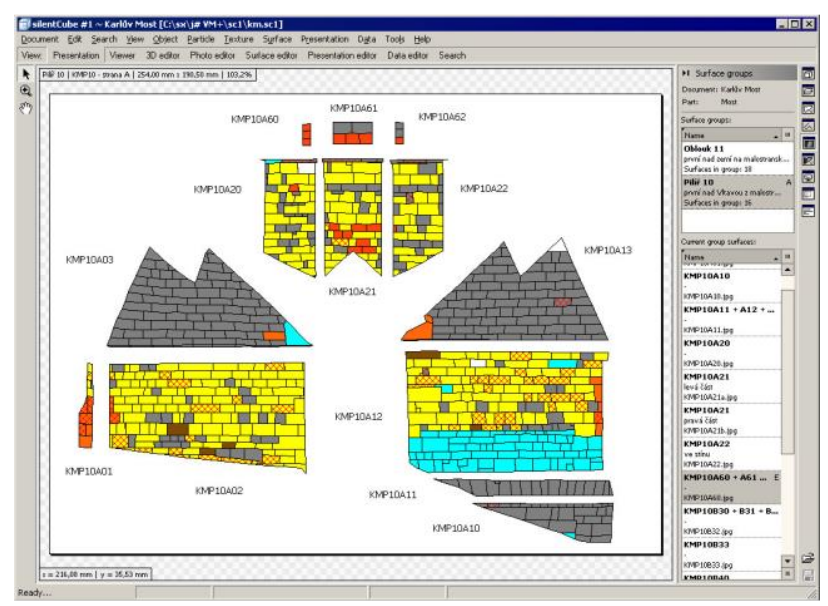

c)

Figure 6 a, b. c. Original developed 3D viewer from 2005 at CTU in Prague, FCE might be called 3D GIS or the predecessor of BIM

Figure 5. 3D model of Charles Bridge in Prague. 


\subsection{Dalal Bridge in Zakho (Iraq / Kurdistan)}

After the success of the documentation and the development of a system for working with descriptive and spatial data, Dalal Bridge in Zakho, Kurdistan, Iraq, was similarly documented in 2008. This bridge probably has parts from the Byzantine era and was in very poor condition. Geodetic measurement and intersection photogrammetric work based on the Photomodeler software was performed in only three days. The documentation of the whole bridge with all stone blocks was carried out, and the analysis of damage to individual parts was also performed (Fig.7). Everything was entered into the above-mentioned 3D system. Unfortunately, this information and other facts were not used for the bridge repair, which did not much respect the historical originality of this object.

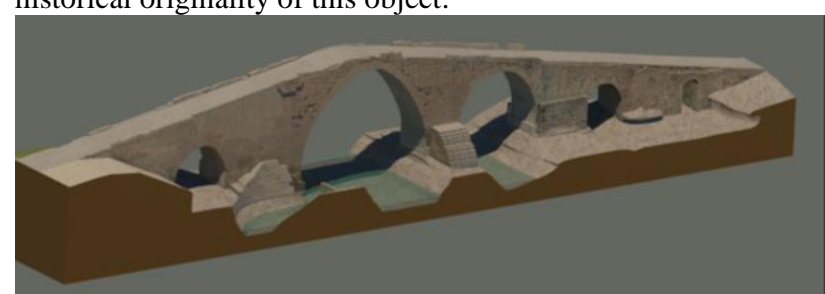

a)

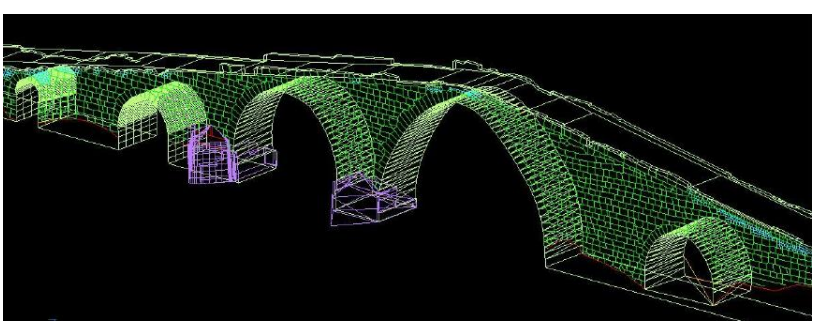

b)

Figure $7 \mathrm{a}, \mathrm{b}$. Dalal Bridge in Zakho (virtual model and vector model)

To a certain extent, it is tragicomic that everyone who saw the 3D-filled 3D system was thrilled. Unfortunately, none of the 3D information systems developed for both the above mentioned bridges has been completed and used. They were ahead of their time and practice in restoring historical objects.

\subsection{Nahúm's shrine in Alqosh (using of VR in restoration process)}

A modern, contemporary approach to the documentation and visualization of historic buildings was used for an important historical monument - the shrine and tomb of the Prophet Nahum in Alqosh (Iraq, Kurdistan), (Fig.8), (Pavelka et al, 2019). The shrine was in critical condition and close to a total collapse. In 2018, based on international activity and funding by Arch International (non-profit organization, "The Alliance for the Restoration of Cultural Heritage “, ARCH), complex 3D documentation of this object was performed using laser scanning and digital intersection photogrammetry (IBMR technology). At the same time, a static securing of the building was made, which was at risk of collapse. New possibilities of spatial documentation and visualization were used in this project. After the static securing of the construction and debris removal, another comprehensive survey was carried out, which showed further details. The resulting 3D models served as original documentation of various states of objects. While the rescue work was in progress, other experts could analyze the failures and discuss the next working steps using the 3D model and virtual reality, which allowed passing through an object without the need to re-visit the facility on-site. In the model, it is possible to measure distances, analyze the situation and virtually fill in non-existing collapsed parts, etc. (Fig.9). Based on a virtual reconstruction and remote consultations, the object was restored and today it is near completion, which is expected next year. After finishing all works, the last and final documentation will be made. The expert information system will thus contain not only three construction time levels, but also found artefacts, material, inscriptions and their translations, etc. Thanks to VR, we can look into the past viewing no longer existing condition of Objects.

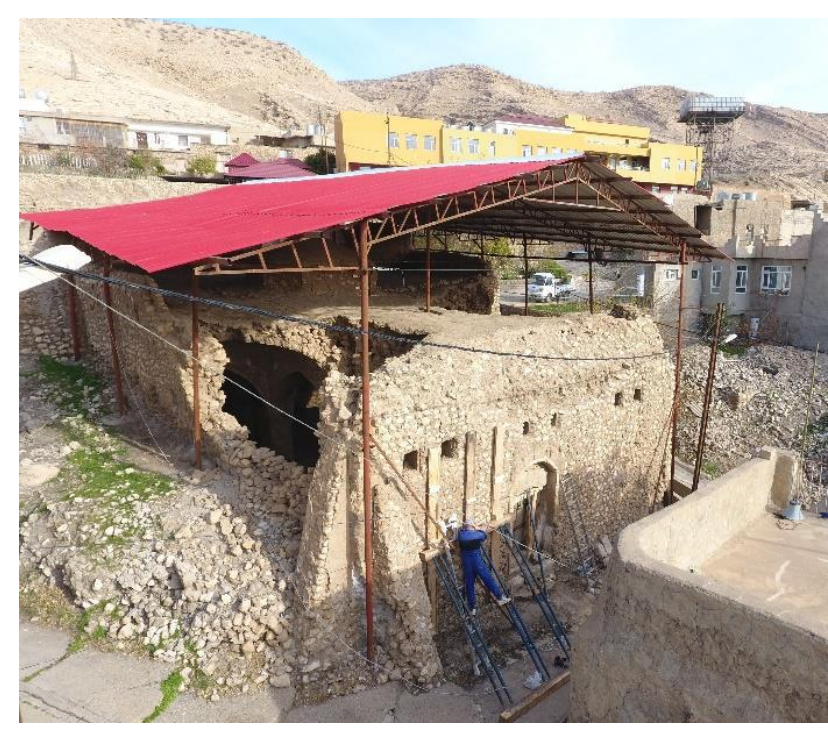

Figure 8. A complex view on the Nahúm's shrine, Alqosh

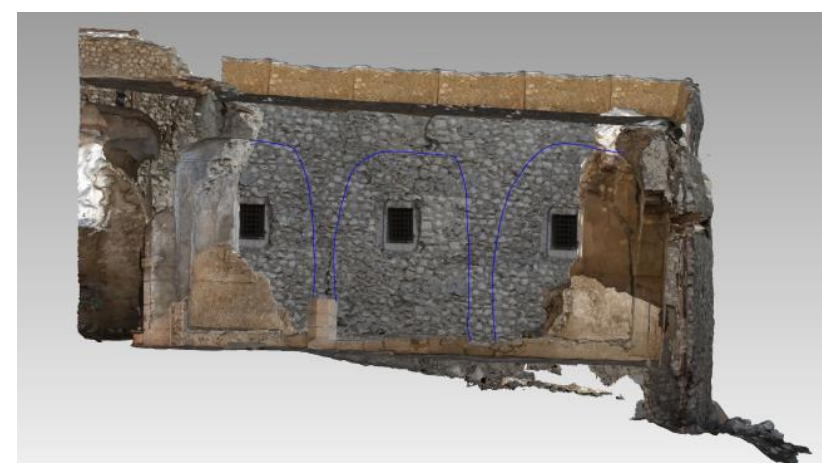

Figure 9. Virtually filled collapsed parts

\subsection{Data transfer to BIM for elder building objects}

The objective of documentation are not always historical objects or buildings. There are large numbers of buildings that need to be renovated due to modernization or reconstruction. It is expected that the reconstructed building will serve many years to come. Typical examples are offices or warehouses, production premises. Modern design companies are already working in BIM, and, in many countries, this is a requirement of the authorities. Therefore, it is necessary to convert the existing object to a BIM object and make the building design or the reconstruction project already in BIM. In simple constructions, today, laser scanning with automatic point clouds joining is used (Fig.10) (Pavelka,jr., Michalík, 2019). The 
process is even more modern and faster with hand-held indoor scanners. Their minor defect is less accurate results in terms of the absolute spatial position of the measured points, which is around a few centimetres.

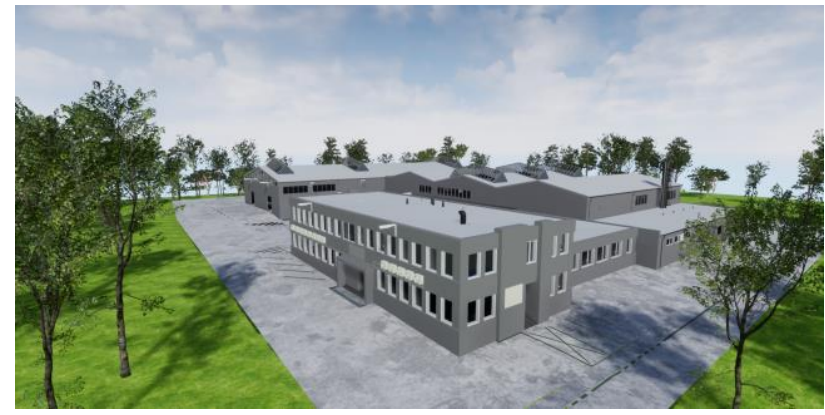

a)

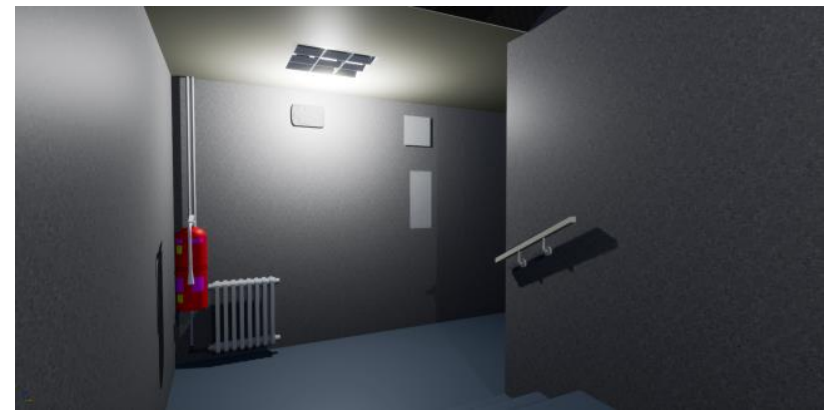

b)

Figure 10 a ,b. Measuring and object modelling based on laser scanned data; an office building and warehouses

\section{CONCLUSION}

The aim of the paper is to show how geomatics and geodetic methods can contribute to the development and digitization in construction. It is shown on examples, how the possibilities of spatial data conversion to BIM have been developed. Especially, new possibilities in the area of restoration of historical objects are mentioned. It turns out that as technology evolves, the transfer to BIM is becoming easier and will significantly increase the percentage of digitization in the construction industry in the near future. Converting a mediumsized object (hundreds of square meters) to BIM can be done in a few days or weeks. It depends on the details and requirements as well as the technique used.

\section{ACKNOWLEDGEMENTS}

This research was partially supported by a student's Internal grant of the Czech Technical University Nr. SGS19/048/OHK1/1T/11 and partially by a grant of the Czech Science Foundation (GACR) Nr. 18-13296S.

\section{REFERENCES}

Dekker, A.-M. 2017. What is "Scan to BIM"? Retrieved January 29, 2019.

https://constructible.trimble.com/construction-industry/what-isscan-to-bim-2

Gleason, D., 2013. Laser Scanning for an Integrated BIM. Constance, October 2013, Retrieved November 11, 2019. https://www.tekla.com/de/trimble-5d/laser-scanning-for-bim.pdf

Hůlková, M., Poloprutský, Z., Raeva, P., Matoušková, E., Housarová, E. 2016. Complex Analysis and Documentation of Historical Buildings Using New Geomatics Methods. The Civil Engineering Journal., 2016(4), 1-8. ISSN 1805-2576.

Kaijaluoto, R., Hyyppä, J., Kukko, A. 2015. Precise Indoor Localization for Mobile Laser Scanner ISPRS - International Archives of the Photogrammetry, Remote Sensing and Spatial Information Sciences. XL-4/W5. 1-6. 10.5194/isprsarchivesXL-4-W5-1-2015.

Matoušková, E., Hůlková, M. Šedina, J. 2016. Historical Plasters Composition Detection Using Reflectance Spectroscopy. The Civil Engineering Journal., 2016(4), 1-7. ISSN 1805-2576.

Pavelka, jr., Michalík, B. 2019. Laser scanning for BIM and results visualization using VR. Measurement, Visualisation and Processing in BIM for Design and Construction Management. International Society of Photogrammetry and Remote Sensing, p. 49-52. vol. XLII-5/W2. ISSN 2194-9034.

Pavelka, K., Hůlková, M., Matoušková, E., Havlín, J. 2016. Exploration of the Charles bridge in Prague by GPR and TLS technology. Interdisciplinarity in Theory and Practice, 2016(11), 264-268. ISSN 2344-2409.

Pavelka, K. 2017. Modern documentation methods in cultural heritage and its benefits. Cultural heritage - perspectives, challenges and future directions. NOVA publishing, New York, USA. p. 113-155. Socisl issues, justice and status. ISBN 978-153612-913-7.

Pavelka, K., Pavelka, K., Šedina, J. 2019. Combined precise documentation and virtual reconstruction of prophet Nahum shrine in Alqosh, Iraq. Int. Arch. Photogramm. Remote Sens. Spatial Inf. Sci. International Society of Photogrammetry and Remote Sensing, p. 909-913. XLII-2-W15. ISSN 2194-9034.

Poloprutský, Z., Fraštia, M., Marčiš, M. 2019. 3D Digital reconstruction based on archived terrestrial photographs from metric camera. Acta Polytechnica., 59(4), 384-398. ISSN 18052363.

Shirer, M., Torchia, M. 2017. "Worldwide Spending on Augmented and Virtual Reality Forecast to Reach \$13.9 Billion in 2017, According to IDC". International Data Corporation. International Data Corporation. Archived from the original on March 19, 2018. Retrieved March 16, 2018.

Šedina, J. Housarová, E. Raeva, P. 2018. Using RPAS for the detection of archaeological objects using multispectral and thermal imaging. European Journal of Remote Sensing. 2018, 2018(6), ISSN 2279-7254.

Tuttas, S., Braun, A., Borrmann, A., Stilla, U. 2014. Comparision of photogrammetric point clouds with BIM building elements for construction progress monitoring. ISPRSInternational Archives of the Photogrammetry, Remote Sensing and Spatial Information Sciences. 1. 341-345.

http://doi/10.5194/isprsarchives-XL-3-341-2014 